\title{
The Portability of Health Care Services Between Guangdong and Macao
}

\author{
Chan Kin Sun ${ }^{1}$, Zhang Rui ${ }^{2 *}$, Siu Yeung Fai ${ }^{3}$ and Wei Hang ${ }^{4}$ \\ ${ }^{1}$ Programme Coordinator of master's in public administration and Assistant Professor, Department of Government and Public \\ Administration, Faculty of Social Sciences, University of Macau, Macao
}

${ }^{2}$ Student of Doctor of Philosophy in Public Administration, Department of Government and Public Administration, Faculty of Social Sciences, University of Macau, Macao

${ }^{3}$ Adjunct Associate Professor, Department of Government and Public Administration, Faculty of Social Sciences, University of Macau, Macao

${ }^{4}$ Supervisor, Global Exchange Office, City University of Macau, Macao

\begin{abstract}
In the context of the development of a healthy city, the use of medical electronic vouchers, the remarkable results of smoking control policy, and the relatively ideal preventive medicine and the control of COVID-19 pandemic, Macao has a sound healthcare system. According to Macao's micro-economy and newly introduction of faculty of medicine in local university, Macao SAR Government has to coordinate medical resources with Guangdong Province in the future, in order to enable local residents to obtain more comprehensive and convenient medical services, i.e. the portability of medical services. Medical doctor resources are an important part of the medical service system and an important factor of the level of medical service. This study uses PEST as the analysis framework to summarize the factors for the development of cross-city medical care and multiple location practice of doctors, so as to conclude that the implementation of medical services in Macao can be. In the direction of portability of medical services, the research results are also summarized by PEST, including the related law amendments (Politically); the importance of the equal status of patients for promoting the marketability of medical service in the Greater Bay Area (Economically); the establishment of an open collaboration mechanism (Socially); the establishment of a professional and patient unified management platform (Technically).
\end{abstract}

KEYWORDS: Guangdong-Hong Kong-Macao greater bay area; Portability; Cross-city medical care; Multiple location practice

\section{INTRODUCTION}

Regarding Medical Security, since Macao initiated in 2004 a "Health City" Scheme hosted by World Health Organization (WHO), Macao has become thereafter an exemplar of Healthy City in its movement, specifically in School Health Promotion, Healthy Buildings, Tobacco and Health, and Healthy Lifestyle Movement [1]. These efforts have received recognition by WHO [2]. And the Health Bureau of Macao SAR Government has put forward a principle of "a sound healthcare system, putting prevention first", under which activities related to hygiene matters in the private and public institutions are to be coordinated. To realize this, several measures to facilitate convenient service are installed, in 2018, medical vouchers are issued in the form of electronic vouchers. And a joint effort with Zhuhai has resulted in a promulgation of "trial points regarding Macao residents residing in Hengqin to be able to participate in Urban Resident Basic Medical Scheme of Zhuhai residents". This provision has enabled Macao residents living in Hengqin to apply for and benefit from identical medical insurance benefits [3]. In 2019, Macao SAR Government has carried out more
Quick Response Code:

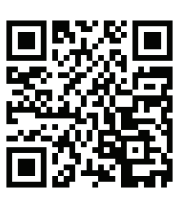

Address for correspondence: Zhang Rui, Student of Doctor of Philosophy in Public Administration, Department of Government and Public Administration, Faculty of Social Sciences, University of Macau

Received: August 21, $2020 \quad$ Published: August 26, 2020

How to cite this article: Chan KS, Zhang R, Siu YF, Wei H. The Portability of Health Care Services Between Guangdong and Macao. 2020 - 2(4) OAJBS.ID.000210. DOI: 10.38125/OAJBS.000210 
comprehensive smoking control policy according to tighter, overall banning out-door standards [4] and this effort has been applied to electronic cigarettes shortly after [5], exemplified by effort of collaboration between Smoking Abstention and Good Health Association (Macao) and Au Hon Sam Charity Association (Macao) in anti-smoking efforts [6]. In 2020, the COVID-19 outbreak affected the World greatly. Macao SAR Government actively tried to curb its spread, making the territory with a low or zero rate of increase in cases. As of August, Macao has not had community outbreak of the virus, with only 46 confirmed cases and 0 case of death. Of these 46 cases, 44 were people from outside and only 2 cases were local people infected. There were no medical personnel infected [7], reflecting a high level of medical services in Macao.

Participating in the development of Guangdong-Hong KongMacao Greater Bay Area, Macao implemented the "Outline DevelopmentPlan for the Guangdong-Hong Kong-Macao Greater Bay Area", fostering areas of service for Macao residents in Guangdong regarding education, retirement, housing, transportation, and also, the cross-border prospects for cross-city social insurance [8]. Later on, in March of 2019, Macao participated in the "Joint Meeting of Municipal Departments of Guangdong-Hong Kong-Macao Cities" and became signatory to the "Framework Agreement on Deepening Guangdong-Hong Kong-Macao Cooperation in the Development of the Greater Bay Area", enabling platform for cooperation, mechanism for effective cooperation, cooperation projects, civic affairs and social welfare maters surrounding elderly service, living security, charity affairs, social organizations, social rescue and exchange and cooperation matters [9]. In 2020, in confronting the pandemic of coronavirus, Macao initiated a "Macao Health Code", and its use in cooperation with its counterpart, "Guangdong Health Code". The interface of the two schemes was installed on May 10 [10] and became in service for the public on July 15. All residents from the Mainland need not undergo isolation and the returning Macao visitors to Guangdong would be exempt from quarantine [11]. The above provisions of health schemes and quarantine exemptions witness a "smart" development of medical and health coordination between the parties, as directed by the state as an important arrangement [12].

From the above background, this study summarizes the prospects for "cross-city medical care" and "multiple-cities practices of medical practitioners" from a PEST (Political, Economic, Social and Technological) analytical framework.

\section{Cross-city Medical Care}

As professionalization in medical service is part and parcel of social service development in Macao, its regularization has become necessary. However, as most Macao medical professionals are trained either in Mainland China or from Taiwan, and a lot of Macao residents get medical treatment in neighboring areas. As professional medical care requires refinement in accessibility by people geographically, the mobility of medical practitioners has become very important. The provision of this service is an important direction in the Guangdong-Hong Kong-Macao Greater Bay Area Strategic Planning. The following uses PEST as an analytical framework to delineate the issue at stake.

\section{The Right of Cross-city Medical Treatment (P)}

Consideration made of cross-city medical treatment in the Greater Bay Area, that is, based on the relevant regulations, certain patients can enjoy treatment in medical institutions external to his/ her city, including medical costs incurred. This provision has already been made in respect of other areas of medical care, such as point- to-point extension of medical institutions providing the service, by proxy care, and branch service of medical institutions participating in insurance schemes [13]. However, the situation in Hong Kong and Macao is different in that their medical system are not based upon low-cost, quality service [14], which may be in variation with arrangements in the Mainland of China. The "cross-city treatment right" in place is akin to the "cross-city patients' rights" [15] under the Guangdong-Hong Kong Macao cooperation scheme, which is in contrast to the across-the-board, self-pay regulation under the "Social Insurance Law". The latter specifies that Chinese nationals can claim reimbursement of medical expenses outside of the residing place in special circumstances, including:

1. The local medical institutions cannot provide the necessary treatment, and upon their certification, the patient can get adequate treatment as a transfer patient

2. The cost covered by insurance for receiving medical care in another institution other than the residing city is lower

3. Agreements by municipal government on outside medical institutions being included in insurance schemes.

To realize the above, further actions need to be made in respect of medical service contracts, standardized contract samples to stipulate details of rights and duties of the signatories. Also, efforts to enhance concepts of evidence, like proofs of registration and medical record, so as to ensure legal protection and procedures in lawsuits and trials. Legal aid service is another area of cross-city medical cooperation. According to the stipulation of the "Legal Aid Regulations of the PRC", legal aid is the responsibility of the Government. To ensure the rights of the patients, legal aid helps in disputes and can remove restrictions on the rights of the patients due to their resident identities.

For the Greater Bay Area residents, rights of medical care should be extended equally. In this regard, the laws in place in EU can be a reference. For example, payment of medical care in another locality should be made by the government of the city in which the patient lives. Actually, this cooperation has been in practice in transfer service between Hong Kong and Macao: Health Bureau of Macao SAR Government and Hospital Authority of Hong Kong has signed a cooperation agreement for 5 years (2018-2023) [16], strengthening cross-city medical treatment and its development.

\section{Strengthening Cross-city Control to Counter Problems brought about by Asymmetrical Information (E)}

The most important problem of medical reform comes from asymmetrical information [17]. This results in the medical quality and makes its control an imminent issue. At present, three areas of control are discernible:

1. Mutual management and cooperation in accounting and clearance of medical insurance; establishing different levels of evaluation implementation; and rational distribution of medical resources in the Greater Bay Area [18].

2. The possibility of control within the trade using organizations and associations therein to regulate internally and to improve on management and professional ethics.

3. To unify on mechanisms intended for management of grievances and complaints, providing communication channels between the cure and the patients. In addition, perhaps the last area is to improve on systems of whistleblowing, trust, and antifraud using information technologies [19]. 
In this regard, Hong Kong is exemplary of using trade organizations and associations in order to enhance development of the medical industry [20], a prospective facilitator of raising medical service in the entire Area.

\section{Establishing Open-style Cooperation Mechanism (S)}

To coordinate policy implementation in the Area, the experience of the EU in cross-city medical management can serve as a good reference. The need to respect individual local policy and the requirement to implement cross-city provisions is reminiscent of the "One-Country, Two-Systems" situation. The realities call for an open-style, effective coordination mode of operation. An open-style coordination mechanism can be realized by a Central Government directed "Guangdong-Hong Kong-Macao Greater Bay Area Medical Security Joint Committee", something like an EU initiated committee from the top. The Committee serves as the core of the mechanism, and is responsible for policy making, implementation, oversight, coordination and supervision of discussion/ expert groups established thereunder. The expert groups gather experts from respective localities.

\section{Unified Medical Management Platform (T)}

Emphasis is on information interface and sharing. Through standardization of medical management in the Greater Bay Area, management efficiency can be enhanced and cost of management can be lowered. Reference can be made to EU's information flow mechanism, interface information advantage, input by greater government public finance and social innovation research, establishing an overall Greater Bay Area medical record and data bank, facilitating prompt and speedy medical service. This service will be particularly useful for short-term stay people doing business, tourism, studies, or for other reasons. A system premised upon something like EU's E111 filing form will make easier insurance clearing. In addition, the medical management platform may include services other than data of patients. For example, it may enable standardization of medical institutions and professionalization of medical personnel, resulting in accreditation and standardization. Of course, in doing so, network security management and protection of privacy of data should be enforced. The case of Guangdong province is illustrative of how Hong Kong and Macao patients, through electronic platform can enable record accessibility and faster payment, a prelude to e-medical care and e-voucher [21]. The latter prospects are a near possibility, with e-payment and featured finance promoted by Macao SAR Government.

\section{Multiple Location Practice of Medical Doctors}

The fact that Hong Kong and Macao have higher economic development is due to their market mechanism, which allows for law amendments and innovation in public sector medical service. This aspect enables multiple locations for medical doctors to provide their service and to facilitate professionalization. Five areas of improvements can facilitate medical policy reform, including legal provision, public hospital reform, mode of certification of medical doctors, the structure of revenue of medical institutions, and the training of medical professionals. Further details of these realities can be delineated again through a framework of PEST analysis done before.

\section{Amendments to Laws and Regulations pertaining to Multiple-location Practice of Medical Doctors (P1)}

The laws governing the medical profession, especially the "Medical Practitioners Laws" is imperfect, not corresponding to realities of the time. Laws, such as "Medical Practitioners Law" and "Temporary Methods on Registration of Medical Practitioners", should be amended to ascertain the role and duties of the medical professionals. This will clarify a number of problems relating the medical professionals to the public, the institutions, the society, and also the relevant government entities [22]. In addition, the current "Notifications on Multiple-location of Medical Practitioners by Hygiene Department" has some contradictions with the "Medical Practitioners Law", making the legality of the latter a standing issue [23].

If multiple-city practice is to happen, ambiguities in "Details on Medical Practitioners Practice", "Temporary Method of Registration of Medical Practitioners" should be clarified, especially regarding localities of practice. The situation is less confronting in Macao, as a lot of medical professionals are graduates of Mainland China Medical schools. This will make graduates of the Macao Medical Professional School and the Macao University of Science and Technology (since 2019) less susceptible to problems arising from the ambiguities of the laws hitherto discussed. In fact, with jointly sponsored hospitals and the more binding CEPA (Closer Economic Partnership Agreement) and the "Guangdong-Hong Kong-Macao Greater Bay Area Development Plan Outline", Macao has found improvements in legal provisions helpful and instrumental.

\section{Expediting Reform on Management System of Public Hospitals (P2)}

Multiple location for medical practitioners is an important issue. However, as public hospitals are human resources managementbased, reforms in areas pertaining to the profession must be considered. Key areas of concern mechanism of management of the profession, salary system, quality and safety management, post, and motivation system. Reference can be drawn from Hong Kong and Macao, especially Hong Kong, which has well-established medical schools and is expanding its experience into Shenzhen, which has witnessed in 2012 a hospital operated by the University of Hong Kong [24]. It is a possibility that Chinese University of Hong Kong may open a medical school there also.

\section{Support on Group-led, Multiple-location Practitioner Mode (E)}

According to established policy, there are three types of practitioners, including on Government directives ones, practice in cooperating hospitals, and the practitioner's own initiative to practice in two or more medical institutions. The three can be differentiated into directive-based or self-initiative-based. The discussion on the center of multi-location of practitioners around these three types of practice. Currently, however, attention has been paid to a group-led, multiple-location mode of practice. The attempt is to allow the market force to play a more prominent role, enabling the professional to be more in line with New Public Management and free market force. Regarding self-initiated multiple-location medical institutions, reference can be made to " $4+1$ " model used in foreign countries, that is, out of five working days, only 4 days should be working in the hospital and the remaining 1 day can be practiced in another hospital or clinics at local level. Another model is " $4+2$ ", which is, out of six working days, only 4 days are hospital work, the remaining 2 days can be at other hospitals or at local level medical care places. This possibility gives the medical practitioners more autonomy and efficient instrumentalities. Most important of all, it affords choice by the medical practitioners [25] to provide professional, high-quality, and safe medical practice. It also enables more insurance-support services. 


\section{Improvements on Income from Medical Revenue and Re-making of Values of Medical Practitioners (S)}

As the current revenue structure of the medical sector is from medicine and medical instruments, the service payment accruing from medical practitioners reflect a deviation from their real labor value. The need for adjustment rationalizing the input of medical practitioners, and their salary reward, is therefore a pressing issue. The remaking of the values of the practitioners should be based on four aspects, including input of time, input of labor, input of knowhow, as well as risk and stress. Based on these four factors, the service and labor value can be realized [26]. Rationalization of labor value should be extended not just to Mainland practitioners, but also to Macao practitioners, so that the overall medical professional can have the incentive they deserve in order to better perform and improve.

\section{Perfecting Entry and Evaluation, Insurance, Oversight and Related Logistic Policies (T)}

A system on entry qualifications of new medical practitioners and their evaluation should be based on their education and training, competence in the profession, working experience, technicalities in medical care, evaluation by patients of the first practicing hospital, successful rescue of emergency cases, passing rate of diagnosis on patients upon entry into hospital, mortality rate and number of medical mishaps, level of rank, responsibility and other criticism there in [27] are important considerations affecting multiplelocation practitioner status. A successful applicant can be awarded a "multi-location practitioner permit", which should be renewed periodically [28], so as to ensure quality and its consistency.

Apart from the necessity of establishing a system of entry standard and evaluation system, in the process, an insurance scheme to protect the medical institution, the patient, the medical doctor has to be installed so as to realize risk-sharing [29]. This provision will facilitate a mechanism to safeguard the interest of all stakeholders [30]. One effect of multiple-location practicing will be the mode of training. The governments should take the lead in standardization, quality-raising, system-binding of the medical personnel. Training should entail continuous and in-service training, giving incentives to self-upgrading and professional ethics of practitioners [31]. With population increase and ageing population, medical service and its needs will become more and more pressing. A multi-faceted medical system seems necessary and realistic, one that provides for the medical profession a clear objective to achieve.

\section{CONCLUSION}

This study has made reference to the experience of the EU and has examined the realities in the Guangdong-Hong Kong-Macao Greater Bay Area. It ventures to suggest two new developments, such as being able to have medical care at different localities and multi-location to practice for practitioners. The study uses PEST as a framework of analysis. Politically, legal provisions while conforming to the national constitution, the Basic Laws (of Hong Kong and Macao) and the "social insurance law", should allow for some amendments to cater to new situations and realities. Economically, people in the Greater Bay Area should be equally entitled to more and better benefits, exploiting more market mechanisms and cooperation opportunities afforded by crosscity arrangements. Socially, two considerations deserve further notice, like establishing an open-style coordination mechanism amongst different cities and establishing joint medical committees for medical security, and a task force/ group comprising experts to work on coordination and communication tasks. Technologically, a unified medical management platform should be established. A social security card along the lines of form $\mathrm{E}$ of the EU can be installed, enabling medical care at different localities and making it more cost-efficient in medical treatment. In this regard, a unified accreditation of the medical practitioners is very much needed.

\section{REFERENCES}

1. (2018) Macao healthy city committee of Macao SAR government. Healthy city 2017 work report and 2018 work plan. Health Department.

2. (2014) World Health Organization-Western Pacific Region. WHO-Macao (China) Healthy city leadership programme for the prevention and control of noncommunicable diseases. World Health Organization.

3. Health Bureau of Macao SAR Government (2019) Zhuhai City Medical Security and Health Department Joint Press Conference Announce that Macao residents living in Hengqin from July 1 can participate in Zhuhai Basic Medical Insurance. Health Bureau of Macao SAR Government.

4. Health Bureau of Macao SAR Government (2018) Entertainments places starting from Jan 1, 2019 will enforce now all-around smoking control, except places established with new standard in place and those granted with permits to those smoking rooms. Health Bureau.

5. Health Bureau of Macao SAR Government (2019) Health department is urging people not to try e-cigarettes, which have multiple hazards and unknown ingredients. Health Bureau.

6. Lou Shenhua (2012) From Relief to Public Welfare: An Observation on the Development of Philanthropy in Macao. Administration 97: 625-643.

7. Government Information Bureau of Macao SAR Government (2020) Macao has no local case reported in 110 days. The $46^{\text {th }}$ confirmed COVID-19 patient in Macao is released today. Government Information Bureau.

8. The State Council of the People's Republic of China (2019) Outline development plan for the Guangdong-Hong Kong-Macao Greater Bay Area. PRC Government.

9. Macao SAR Government (2019) Social Work Department signing to Guangdong-Hong Kong-Macao City Great Bay Area Civil Affairs Coordination for Development Co-operate Framework Agreement. Macao SAR Government.

10. Government Information Bureau of Macao SAR Government (2020) Mutual Recognition of Macao Health Code and Guangdong Health Code mutual entry, Guangdong Macao entry policy remain unchanged, holder of Health code does not mean exemption from isolation observation. Government Information Bureau.

11. Government Information Bureau of Macao SAR Government (2020) Tomorrow Guangdong-Macao people of two places regular travel effectuates new measures. Emergency Co-ordination Centre urged residents to complete the health code conversion first to avoid crowd gathering. Government Information Bureau.

12. The State Council of the People's Republic of China (2019) Outline Development Plan for the Guangdong-Hong Kong-Macao Greater Bay Area. PRC Government.

13.Zhao Bin (2016) Studying on medical insurance in cross-territory treatment perfecting the management and service mechanism. Social Security 4: 55- 62.

14.Yi Longfei (2014) The operation and revelation of UK, Singapore and China-HK's all people medical. Chinese Journal of Health Policy 7(5): 49-55.

15. Nie J (2014) EU Cross-territory rights of patient's medical treatment directive, implementation and reference. Global Science, Technology and Economic Outlook 29(8): 8-12.

16. Government Information Bureau of Macao SAR Government (2018) Hygiene department and HK SAR medical management authority signed a cooperation agreement for 2018-2023. Government Information Bureau. 
17. Wang Y (2008) Medical market: US experience and its revelation for China. China's economic system reform 2: 167-170.

18. Huang Y, Wang C (2016) Research on advantages, Difficulties and Countermeasures of industry Association in external supervision of public Hospitals. Chinese Health Quality Management 23(3): 118- 121.

19. National Development and Reform Commission of the People's Republic of China (2018) Concerning seriously memorandum of cooperation on joint disciplinary punishment for persons responsible for acts of dishonesty which seriously endanger the normal medical order. National Development and Reform Commission.

20. Luo E (2012) Explanation on HK's industry association and reference for mainland China. Social Sciences Review 56-57.

21. Health Bureau of Macao SAR Government (2018) Electronic health record sharing system pilot project self-registration service opens tomorrow. Health Bureau.

22. Dou F (2016) Regarding multi-point practice's study and suggestions brought forth by medical practitioners' law. Journal of Modern Clinical Medicine 377-379.

23. Wang A, Zheng X, Gao S (2014) Analysis on the legal problems of doctors' multi-point practice. Chinese Journal of Health Policy 1.

24. Health and Family Planning Commission of Shenzhen Municipal Government (2019) Open information-university of Hong Kong
Shenzhen Hospital. Health and Family Planning Commission.

25.Zheng W, Huang F, Lei M. Difficulty in multi-location of medical practitioners, reasons and policy responses. Health Economics Research 12: $11-13$.

26. Ouyang M, LI H, Wang D (2016) Preliminary responses on project for medical establishment system on indices on labor value medical practitioners. Chinese Health Service Management 3: 164-166.

27. Bao C, Zhu Yi, Ljiu Y, Liu Y, Cai J, Bai Y (2013) The challenges and responses to multi-locations practice of medical practitioners in China. Chinese Health Resources 16(2): 112-113.

28. Yan M, Yan S (2012) Problems and Responses to Doctors' Multi-locations Practice. Chinese Hospital Management 5: 8-9.

29. Wu M, Liu Y, Li X (2013) Analysis on responses to promoting public hospital doctors bases on multiple-locations practice basis. China Hospitals 8: 24-25.

30. Yi Y, Dai F, Zhang K (2016) Based on the perspective of conflict of interest to view multiple wins of multi-locations practice. Jiangsu Healthcare Administration 2: 16-17.

31. Chinese Medical Doctor Association (2015) White paper on the practice of doctors in China. Chinese Medical Doctor Association. 